\title{
Laminar Profile and Physiology of the $\alpha$ Rhythm in Primary Visual, Auditory, and Somatosensory Regions of Neocortex
}

\author{
(D)Saskia Haegens, ${ }^{1,2}$ Annamaria Barczak, ${ }^{2,3}$ Gabriella Musacchia, ${ }^{4,5}{ }^{\circledR}$ Michael L. Lipton, ${ }^{6}$ Ashesh D. Mehta, \\ Peter Lakatos, ${ }^{2,3}$ and Charles E. Schroeder ${ }^{1,2}$ \\ ${ }^{1}$ Department of Psychiatry, Columbia University College of Physicians and Surgeons, New York, New York 10032, ${ }^{2}$ Cognitive Neuroscience and \\ Schizophrenia Program, Nathan Kline Institute, Orangeburg, New York 10962, ${ }^{3}$ Department of Neuroscience and Physiology, New York University School \\ of Medicine, New York, New York 10016, ${ }^{4}$ Department of Otolaryngology, Head and Neck Surgery, Stanford University, Stanford, California $94303,{ }^{5}$ Center \\ for Molecular and Behavioral Neuroscience, Rutgers University, Newark, New Jersey 07102, ${ }^{\circ}$ Department of Radiology, Albert Einstein College of Medicine, \\ Bronx, New York 10461, and 'Department of Neurosurgery, Hofstra North Shore-LIJ School of Medicine and Feinstein Institute for Medical Research, \\ Manhasset, New York 11030
}

The functional significance of the $\alpha$ rhythm is widely debated. It has been proposed that $\alpha$ reflects sensory inhibition and/or a temporal sampling or "parsing" mechanism. There is also continuing disagreement over the more fundamental questions of which cortical layers generate $\alpha$ rhythms and whether the generation of $\alpha$ is equivalent across sensory systems. To address these latter questions, we analyzed laminar profiles of local field potentials (LFPs) and concomitant multiunit activity (MUA) from macaque V1, S1, and A1 during both spontaneous activity and sensory stimulation. Current source density (CSD) analysis of laminar LFP profiles revealed $\alpha$ current generators in the supragranular, granular, and infragranular layers. MUA phase-locked to local current source/sink configurations confirmed that $\alpha$ rhythms index local neuronal excitability fluctuations. CSD-defined $\alpha$ generators were strongest in the supragranular layers, whereas LFP $\alpha$ power was greatest in the infragranular layers, consistent with some of the previous reports. The discrepancy between LFP and CSD findings appears to be attributable to contamination of the infragranular LFP signal by activity that is volume-conducted from the stronger supragranular $\alpha$ generators. The presence of $\alpha$ generators across cortical depth in V1, S1, and A1 suggests the involvement of $\alpha$ in feedforward as well as feedback processes and is consistent with the view that $\alpha$ rhythms, perhaps in addition to a role in sensory inhibition, may parse sensory input streams in a way that facilitates communication across cortical areas.

Key words: $\alpha$ rhythm; auditory; laminar; somatosensory; visual

Significance Statement

The $\alpha$ rhythm is thought to reflect sensory inhibition and/or a temporal parsing mechanism. Here, we address two outstanding issues: (1) whether $\alpha$ is a general mechanism across sensory systems and (2) which cortical layers generate $\alpha$ oscillations. Using intracranial recordings from macaque $\mathrm{V} 1, \mathrm{~S} 1$, and $\mathrm{A} 1$, we show $\alpha$ band activity with a similar spectral and laminar profile in each of these sensory areas. Furthermore, $\alpha$ generators were present in each of the cortical layers, with a strong source in superficial layers. We argue that previous findings, locating $\alpha$ generators exclusively in the deeper layers, were biased because of use of less locally specific local field potential measurements. The laminar distribution of $\alpha$ band activity appears more complex than generally assumed.

\section{Introduction}

Oscillatory activity in the $\alpha$ band $(8-14 \mathrm{~Hz})$ is thought to play a key role in perception and behavior, in particular, by supporting

Received Feb. 5, 2015; revised Sept. 2, 2015; accepted Sept. 13, 2015

Author contributions: S.H., A.B., G.M., M.L.L., A.D.M., P.L., and C.E.S. designed research; S.H., A.B., G.M., M.L.L., and A.D.M. performed research; S.H., P.L., and C.E.S. analyzed data; S.H., P.L., and C.E.S. wrote the paper.

This work was supported by NIH Grants MH060358, DC011490, DC012947, P50MH086385, and F32DC009918 and NWO Rubicon Grant 446.11.009. We thank the Nathan Kline Institute for Psychiatric Research for supplementary support for the research and our colleagues (in alphabetical order) Drs. Arnaud Falchier, Mark Klinger, Gary Linn, and Deborah Ross for consultation and essential assistance in all phases of the work. sensory suppression and/or temporal framing (Klimesch et al., 2007; Palva and Palva, 2007; Jensen and Mazaheri, 2010; Foxe and Snyder, 2011). Despite evidence for this and other $\alpha$ functions, both in humans (Thut et al., 2006; Haegens et al., 2010, 2011a;

The authors declare no competing financial interests.

Correspondence should be addressed to Saskia Haegens, Department of Neurological Surgery, Columbia University College of Physicians and Surgeons, 650 West 168 Street, P\&S 5-447, New York, NY 10032. E-mail: shaegens@gmail.com.

DOI:10.1523/JNEUROSCI.0600-15.2015

Copyright $\odot 2015$ the authors $\quad 0270-6474 / 15 / 3514341-12 \$ 15.00 / 0$ 
Zhang and Ding, 2010; Gould et al., 2011) and monkeys (Bollimunta et al., 2008, 2011; Haegens et al., 2011b; Mo et al., 2011; Saalmann et al., 2012; Haegens et al., 2014), several key mechanistic questions remain.

First, previous studies suggested that layer 5 pyramidal cells in visual cortex operate as cortical pacemakers that control $\alpha$ dynamics (Steriade et al., 1990; Lopes da Silva, 1991). These excitatory neurons receive inhibitory feedback from GABAergic interneurons, and computational modeling shows that this interaction can produce $\alpha$ oscillations (Jones et al., 2000, 2009). Partly driven by this idea, recent investigations in visual cortex have concluded that $\alpha$ operates primarily in the infragranular layers (Buffalo et al., 2011; Spaak et al., 2012), whereas studies showing indirect evidence for this, have been taken as further support for the " $\alpha$ operates in deep layers" thesis (Maier et al., 2010, 2011). However, direct empirical measurements dispute this conclusion, indicating strong $\alpha$ current generators in supragranular and granular layers as well (Bollimunta et al., 2008, 2011; Mo et al., 2011), with V1 granular and infragranular layers containing primary local pacemakers. As the supragranular and infragranular pyramidal neurons have distinctive patterns of (sub)cortical connections and contrasting roles in feedforward and feedback processing, our first goal was to quantitatively define the laminar profile of $\alpha$ generation in V1.

Second, although visual and somatosensory $\alpha$ rhythms appear functionally analogous (Haegens et al., 2010, 2011a), it is unclear whether they are generated by comparable neuronal populations and operate similarly across cortical layers. The same uncertainty applies to auditory $\alpha$, and, in fact, there is some doubt as to whether $\alpha$ is actually generated in auditory cortex itself (Tiihonen et al., 1991; Kaiser et al., 2007; Banerjee et al., 2011). As a first step in determining whether $\alpha$ reflects a general mechanism operating across sensory modalities (Klimesch, 1999; Başar, 2012), we directly compared the laminar distribution and physiological properties of $\alpha$ oscillations recorded in visual, somatosensory, and auditory cortices.

Our findings show that the laminar distribution of $\alpha$ oscillations is similar across sensory areas and that these $\alpha$ oscillations receive contributions from transmembrane currents in all layers. These findings do not fit well with the view that $\alpha$ arises primarily from the infragranular layers and thus reflects mainly "feedback" operations (van Kerkoerle et al., 2014). In combination with other recent findings (Busch et al., 2009; Dugué et al., 2011; Saalmann et al., 2012), our results argue instead that $\alpha$ operates in both feedforward and feedback processes. While not disputing the perceptual suppression account, we suggest that $\alpha$, along with $\delta$ and $\theta$ rhythms (Luo and Poeppel, 2007; Schroeder et al., 2008; Lakatos et al., 2013), provides a mechanism for parsing sensory information into "packets" and thus helps to coordinate activity across ensembles in other (sub)cortical regions.

\section{Materials and Methods}

Data acquisition. With two exceptions (see below, monkeys Wi and Jj), data for this study were taken from two well characterized datasets, including seven animals (four female, three male). Linear array multielectrodes (Barna et al., 1981) were used, with either 14 contacts equally spaced at 150 or $200 \mu \mathrm{m}$ or 23 contacts with 100 or $200 \mu \mathrm{m}$ spacing (Neurotrack). Contact impedances were between 0.1 and $0.3 \mathrm{M} \Omega$.

We obtained laminar profiles of spontaneous and somatosensory event-related local field potentials (LFPs) and multiunit activity (MUA) in S1 (area 3b) from a dataset collected in three monkeys [surgical, recording, and laminar identification procedures described by Lipton et al. $(2006,2010)]$, including 18 penetrations in monkey Bt and 11 in monkey $\mathrm{Pb}$. For this study, we also included data collected during 12 additional
Table 1. Recording overview

\begin{tabular}{|c|c|c|c|}
\hline \multirow[b]{2}{*}{ Animal } & \multicolumn{3}{|l|}{ Area } \\
\hline & $S 1$ & V1 & $\mathrm{A} 1$ \\
\hline $\mathrm{Bt}$ & $\begin{array}{l}N_{\text {total }}=18 \\
N_{\text {spont }}=13 \\
N_{\text {stim }}=17\end{array}$ & & \\
\hline $\mathrm{Pb}$ & $\begin{array}{l}N_{\text {total }}=11 \\
N_{\text {spont }}=4 \\
N_{\text {stim }}=9\end{array}$ & & \\
\hline Wi & $\begin{array}{l}N_{\text {total }}=12 \\
N_{\text {spont }}=12 \\
N_{\text {stim }}=10\end{array}$ & & \\
\hline$B d$ & & $\begin{array}{l}N_{\text {total }}=13 \\
N_{\text {spont }}=11 \\
N_{\text {stim }}=13\end{array}$ & $\begin{array}{l}N_{\text {total }}=2 \\
N_{\text {spont }}=2 \\
N_{\text {stim }}=2\end{array}$ \\
\hline $\mathrm{Vt}$ & & $\begin{array}{l}N_{\text {total }}=11 \\
N_{\text {spont }}=11 \\
N_{\text {stim }}=11\end{array}$ & $\begin{array}{l}N_{\text {total }}=15 \\
N_{\text {spont }}=15 \\
N_{\text {stim }}=15\end{array}$ \\
\hline $\mathrm{Bu}$ & & & $\begin{array}{l}N_{\text {total }}=2 \\
N_{\text {spont }}=2 \\
N_{\text {stim }}=2\end{array}$ \\
\hline $\mathrm{Jj}$ & & $N_{\text {total }}=2$ (reference control) & \\
\hline Total & $\begin{array}{l}N_{\text {total }}=41 \\
N_{\text {spont }}=29 \\
N_{\text {stim }}=36\end{array}$ & $\begin{array}{l}N_{\text {total }}=26 \\
N_{\text {spont }}=23 \\
N_{\text {stim }}=24\end{array}$ & $\begin{array}{l}N_{\text {total }}=19 \\
N_{\text {spont }}=19 \\
N_{\text {stim }}=19\end{array}$ \\
\hline
\end{tabular}

Data are the number of penetrations for each animal per area and per condition (spont, spontaneous/resting state condition; stim, passive stimulation condition). Note that not all conditions were available for all penetrations.

penetrations in Wi. Furthermore, we used a dataset from V1 and A1 experiments collected in three monkeys during visual and auditory stimulation [surgical, recording, and laminar identification procedures described by Mehta et al. (2000) and Lakatos et al. $(2008,2009)$ ], including the following: for $\mathrm{V} 1,13$ penetrations in monkey Bd and 11 in monkey $\mathrm{Vt}$; for $\mathrm{A} 1,2$ penetrations in $\mathrm{Bd}, 15$ in $\mathrm{Vt}$, and 2 in monkey Bu. Reference electrodes for $\mathrm{V} 1$ and $\mathrm{A} 1$ recordings were epidural contacts placed over midline frontal and occipital regions, respectively. References for S1 recordings were placed epidurally over the contralateral sensorimotor cortex. To explore the effects of reference location, we also conducted additional recordings from $\mathrm{V} 1$ in $\mathrm{Jj}$ (two penetrations); reference details are given in Figure 7. See Table 1 for an overview of recording sessions in each animal.

Surgical procedures. Relevant details concerning preparatory surgical procedures for the pre-existing datasets were reported previously (Mehta et al., 2000; Lakatos et al., 2008, 2009; Lipton et al., 2010). New data for this study were recorded from two monkeys that were engaged in other projects in our laboratory. Relevant details of surgical preparation for these monkeys ( $\mathrm{Jj}$ and $\mathrm{Wi}$ ) are described here. All procedures were approved in advance by the Institutional Animal Care and Use Committee at the Nathan Kline Institute. The purpose of the surgery was to implant a titanium head post and recording chambers to ensure head immobilization during training/recording and allow for electrode access to the visual (for $\mathrm{Jj}$ ) and somatosensory (for $\mathrm{Wi}$ ) cortices. The surgery was performed using standard aseptic techniques under general anesthesia ( $1-2 \%$ isoflurane and $30-50 \% \mathrm{~N}_{2} \mathrm{O}$ ). The tissue overlying the calvarium was retracted, and appropriate portions of the cranium were removed. The neocortex and overlying dura were left intact. To allow electrode access to the brain and to promote an orderly pattern of sampling across the surface of V1 and S1, custom recording chambers (Crist Instrument Company) incorporating electrode guide grids were placed over the lateral operculum surface of $\mathrm{V} 1$ (in $\mathrm{Jj}$ ). These chambers and grids were angled so that the electrode track is perpendicular to the surface of $\mathrm{V} 1$, as determined by preimplant MRI (Schroeder et al., 1998). Similar MRI and implantation procedures were used to position chambers over the lateral extent of the central sulcus at an anteroposterior angle suitable for mak- 

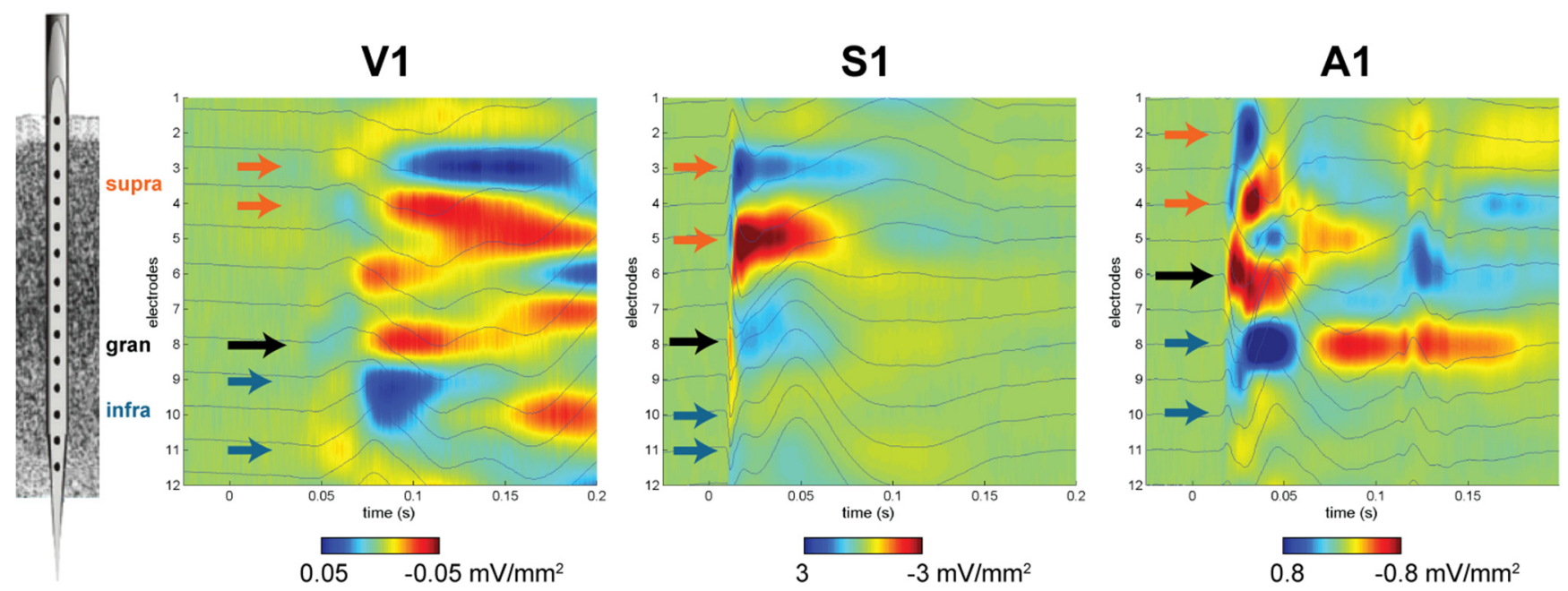

Figure 1. Laminar profile of evoked response. CSD profiles of the evoked response to stimulation in each of the modalities. Left, One representative recording site in V1, showing a visual evoked response to a flash stimulus (average over $n=1531$ trials). The granular layer (gran) is indicated by a single black arrow and the supragranular layers (supra) and infragranular layers (infra) by double orange and blue arrows, respectively. Middle, Similarly for $\mathrm{S1}$, showing a somatosensory evoked response to contralateral median nerve stimulation $(n=100)$. Right, Similarly for A1, showing an auditory evoked response to $60 \mathrm{~dB}$ pure tones $(n=286)$. Note how the evoked LFP (blue traces plotted on top of the CSD profile, presented in arbitrary units) is strongest in deeper layers.

ing electrode penetrations of area $3 \mathrm{~b}$ (in Wi), approximately orthogonal to its lamination pattern (Lipton et al., 2006). Chambers were placed over small, appropriately shaped craniotomies and set to rest against the skull surrounding the craniotomy, with dura left intact. The chambers, along with the head post (Crist Instrument Company), were secured to the skull with titanium orthopedic screws and embedded in bone cement. A recovery time of 6 weeks was allowed before continuing any behavioral training and/or beginning data collection.

Experimental paradigm. For the $\mathrm{S} 1$ recordings, two experimental conditions were used: (1) spontaneous "resting" recordings during which the monkey was awake (average length of $4 \mathrm{~min}$ ); and (2) passive contralateral median nerve stimulation $(200 \mu$ s duration square-wave pulse at $2 \mathrm{~Hz}$; mean, 140 stimuli per session), with stimulus intensity titrated before each session to just below the threshold for the adductor pollicis brevis twitch (Lipton et al., 2010).

The $\mathrm{S} 1$ experiments entailed recording during periods of spontaneous (resting) activity and during passive stimulation. V1 and A1 recordings were taken from studies in which monkeys were trained to perform an intermodal (visual/auditory) selective attention task, which required them to attend to and discriminate stimuli within one modality while ignoring stimuli in the other modality (Mehta et al., 2000; Lakatos et al., $2008,2009)$. To approximate as closely as possible the conditions of the S1 experiments, for V1 recordings, we only analyzed two auditoryattention conditions. First, we examined ongoing activity in V1 while auditory-only stimuli $(50 \mathrm{~ms}, 70 \mathrm{~dB}$, binaural pure tone at $2 \mathrm{kHz}$; mean, 170 stimuli per session) were presented and attended $(\sim 1.5 \mathrm{~min}$ per recording site). As auditory stimuli do not produce evoked responses in $\mathrm{V} 1$, this corresponds to the spontaneous condition in the S1 recordings. Second, we examined responses to visual distracters (centrally presented, $10 \mu$ s, red light flash; mean rate, $1.5 \mathrm{~Hz}$; mean, $\sim 1000$ stimuli per session) while the monkey was attending to auditory targets. This (although not perfectly matched) corresponds reasonably to the passive stimulation condition in the S1 study, in which the subjects were well habituated to the stimuli and likely ignored them most of the time. Using the same logic, for A1, we analyzed two visual-attention conditions: the ongoing activity in A1 while visual-only stimuli were presented and attended to and the responses to auditory distracters while the monkey was attending to visual targets.

Data analysis. For data analysis, we used custom-built Matlab code and the FieldTrip toolbox (Oostenveld et al., 2011). We examined the laminar profile of the $\alpha$ rhythm in (1) the LFP signal as recorded; (2) its first spatial derivative, i.e., bipolar derivation between two electrode channels; and 3) its second derivative, the current source density (CSD) signal, which allows localization of underlying current generators (Nicholson,
1973; Nicholson and Freeman, 1975; Mitzdorf, 1985; Schroeder et al., 1998). For the CSD computation, we used a nearest-neighbor approach, and for the bipolar derivation, we used a next-nearest-neighbor approach to match the spatial scale of the bipolar signal to that of the CSD signal. Specifically, CSD for location $\mathrm{x}$ was computed using the LFP signal at $\mathrm{x}$ and at adjacent (nearest-neighbor) recording sites $\mathrm{x}-1$ and $\mathrm{x}+1$, whereas the bipolar derivation for that same location was computed by subtracting the LFP signal at $\mathrm{x}-1$ from the (next-nearest-neighbor) signal at $x+1$. These measures were computed on a trial-by-trial basis. MUA was high-pass filtered at $500 \mathrm{~Hz}$ and rectified.

Using the characteristic laminar profile of the evoked response (contralateral median nerve stimulation for S1, flash stimuli for V1, $60 \mathrm{~dB}$ pure tones for A1), the functional identification of supragranular, granular, and infragranular cortical layers is straightforward based on our previous studies (Peterson et al., 1995; Schroeder et al., 1998, 2001). We picked one to two channels clearly within each layer, for each recording site (Fig. 1). In A1, S1, and V1, the location of the granular layer(s) is marked by a short-latency current sink, which is usually accompanied by a sharp increase in MUA. The base of layer 3 in these areas, and the boundary between supragranular and granular layers, is marked by the polarity inversion of the initial positive LFP component. Note that when light flash stimulation is applied, the initial V1 LFP component is a prominent negativity, which undergoes polarity inversion at the site of the early current $\operatorname{sink}(\mathrm{s}$ ) in layer 4 (Schroeder et al., 1991, 1998). V1 is unique in having a very wide layer 4 ; it is $\sim 500 \mu \mathrm{m}$ thick compared with $\sim 150$ $\mu \mathrm{m}$ thick in A1 and S1 (Lund, 1988). It is the following component (P55; Schroeder et al., 1991, 1998) that corresponds to the initial positive components in A1 (P30; Steinschneider et al., 1992) and S1 (P20; Peterson et al., 1995). The supragranular layers usually display a clear source over sink pattern. All further spectral analysis was restricted to these selected channels, to be sure that effects could be reliably attributed to one of the three layers.

Data were segmented into $500 \mathrm{~ms}$ epochs for the spontaneous/ ongoing-activity sessions, and for the stimulus trials, $500 \mathrm{~ms}$ prestimulus windows were taken. Note that this inevitably includes the evoked response to the preceding stimulus; the interstimulus interval was as follows: for S1, fixed at $500 \mathrm{~ms}$; for V1/A1, varied between 500 and $800 \mathrm{~ms}$ (mean, $650 \mathrm{~ms}$ ). Segments were multiplied with a Hanning taper, and power spectra $(5-30 \mathrm{~Hz})$ were computed using a fast Fourier transform. Spectra were averaged over trials and normalized with the average spectral power across layers, for each recording site separately.

To compute CSD and MUA profiles realigned to $\alpha$ phase, the CSD signal was bandpass filtered in the $\alpha$ range ( $8-14 \mathrm{~Hz}$; Butterworth filter), after which the $\alpha$ troughs were detected (i.e., all negative peaks) in one 
A
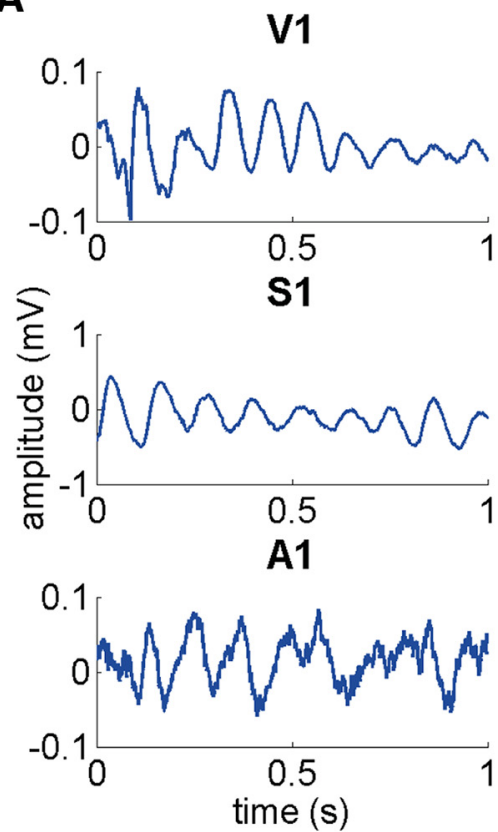

V1 (filtered)

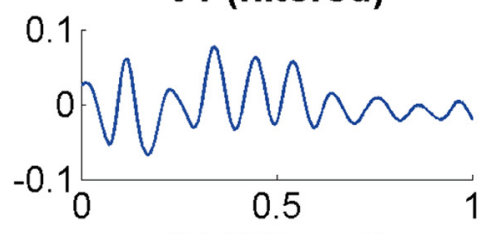

S1 (filtered)
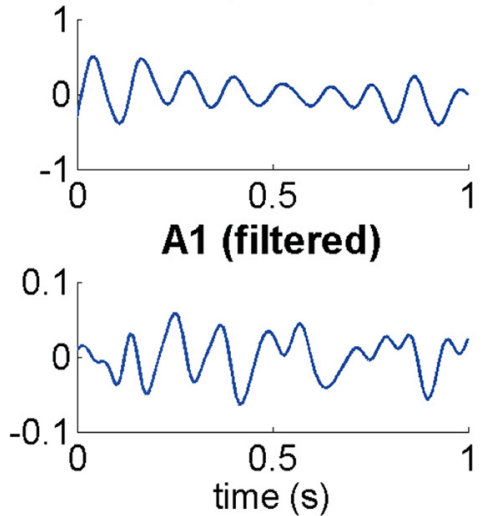

B
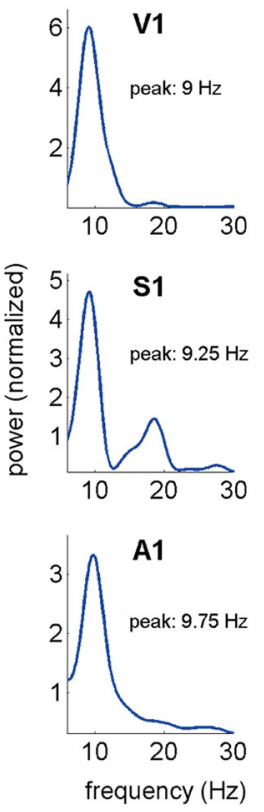

Figure 2. $\alpha$ oscillations in the monkey sensory cortex. A, Representative 1s LFP segments from three different monkeys, for each of the primary sensory areas (top, V1; middle, S1; bottom, A1), showing raw unfiltered data (left) and low-pass-filtered data ( $20 \mathrm{~Hz}$; right). $\boldsymbol{B}$, Power spectra for these sites, averaged over the recording session.

reference channel (e.g., the granular channel). All data (across channels, for both CSD and MUA) were realigned to these troughs, cut into $250 \mathrm{~ms}$ data segments, and averaged, which gives the $\alpha$-realigned CSD and MUA profiles. This is similar to realignment procedures used in previous work (Bollimunta et al., 2008, 2011; van Kerkoerle et al., 2014), except here we realign to $\alpha$ in the CSD, not the LFP.

\section{Results}

To give a clear idea of the nature of the data, and to illustrate the selection of supragranular, granular, and infragranular recordings for the following quantitative analyses, Figure 1 displays representative profiles of stimulus-evoked activity in V1, S1, and A1. In each case, there is initial activation (current sink) in the middle granular layers (Fig. 1, single arrows), followed at short latency by current source/sink configurations in supragranular and infragranular layers (Fig. 1, double arrows). This basic laminar activation sequence is stereotypic in $\mathrm{V} 1, \mathrm{~S} 1$, and $\mathrm{A} 1$ and provides the means to reliably identify cortical layers (Schroeder et al., 1991, 1998; Steinschneider et al., 1992; Peterson et al., 1995). The channels selected for the supragranular, granular, and infragranular layer analyses correspond to locations of prominent current sinks in these layers; channel selection was performed similarly for each experiment (electrode penetration).

\section{Correspondence of $\boldsymbol{\alpha}$ across sensory cortices}

First, to illustrate the similarity of ongoing $\alpha$ oscillatory activity across cortical areas, we display 1 s example segments of ongoing activity across cortical layers from recording sessions in three different monkeys, for V1 (during auditory stimulation, $\sim 2$ min of continuous data), S1 (during rest, $4.5 \mathrm{~min}$ ), and A1 (during visual stimulation, $6.5 \mathrm{~min}$ ). We computed power spectra on the epoched data (500 ms segments), showing the existence of a prominent $\alpha$ rhythm in ongoing LFP activity in each of these primary sensory regions (Fig. 2). A prominent $\beta$ peak was also apparent in S1.
The $\alpha$ rhythm reflects excitability fluctuations

Second, using the spontaneous recordings in S1, we investigated the relationship between $\alpha$ oscillations across the laminae and neuronal firing measured as MUA. We computed CSD and MUA profiles that were aligned to the $\alpha$ phase (i.e., trough of the $\alpha$ cycle) as observed in the supragranular, granular, and infragranular layers, respectively (Fig. $3 A, B$ ). We then investigated how granular MUA was modulated by the $\operatorname{CSD} \alpha$ phase for each of the layers. When aligned with the $\alpha$ sink (i.e., the negative peak in the local $\alpha$ oscillation) in supragranular layers, a phasic modulation of MUA in the middle layers becomes apparent, with MUA increase aligned to the sink. Similarly, when locked to the granular and infragranular $\alpha$ cycle, MUA is phasically modulated; note that directionality of the effect (strongest/ weakest during sink) depends on the channel reflecting an active versus passive current sink [also see Lakatos et al. (2013), their Fig. S1]. These modulatory effects of CSD $\alpha$ phase on MUA activity were statistically significant across all recording sites (Fig. 3C; aligned to supragranular $\alpha$ sink: absolute modulation, $t_{(56)}=10.46$, Bonferroni-corrected $p<0.001$; granular sink: $t_{(28)}=6.67, p<$ 0.001 ; infragranular sink: $\left.t_{(28)}=6.29, p<0.001\right)$. These results confirm that locally generated $\alpha$ can be observed in the supragranular, granular, and infragranular cortical layers in S1 and that it indexes local neuronal excitability fluctuations.

Repeating this analysis for $\mathrm{V} 1$ and $\mathrm{A} 1$ showed the same patterns (V1, aligned to supragranular $\alpha$ sink: $t_{(45)}=4.33$, Bonferronicorrected $p<0.001$; granular sink: $t_{(22)}=3.96, p<0.01$; infragranular sink: $t_{(37)}=4.72, p<0.001 ; \mathrm{A} 1$, aligned to supragranular $\alpha$ sink: $t_{(37)}=7.04$, Bonferroni-corrected $p<0.001$; granular sink: $t_{(18)}=$ $5.36, p<0.001$; infragranular sink: $\left.t_{(37)}=7.54, p<0.001\right)$, confirming a similar relationship between ongoing $\alpha$ and neuronal firing across sensory modalities.

\section{Laminar distributions of $\alpha$ amplitude}

Next, we asked in which layer $\alpha$ activity is largest. For each recording site, we computed power spectra for each of the layers, 
A
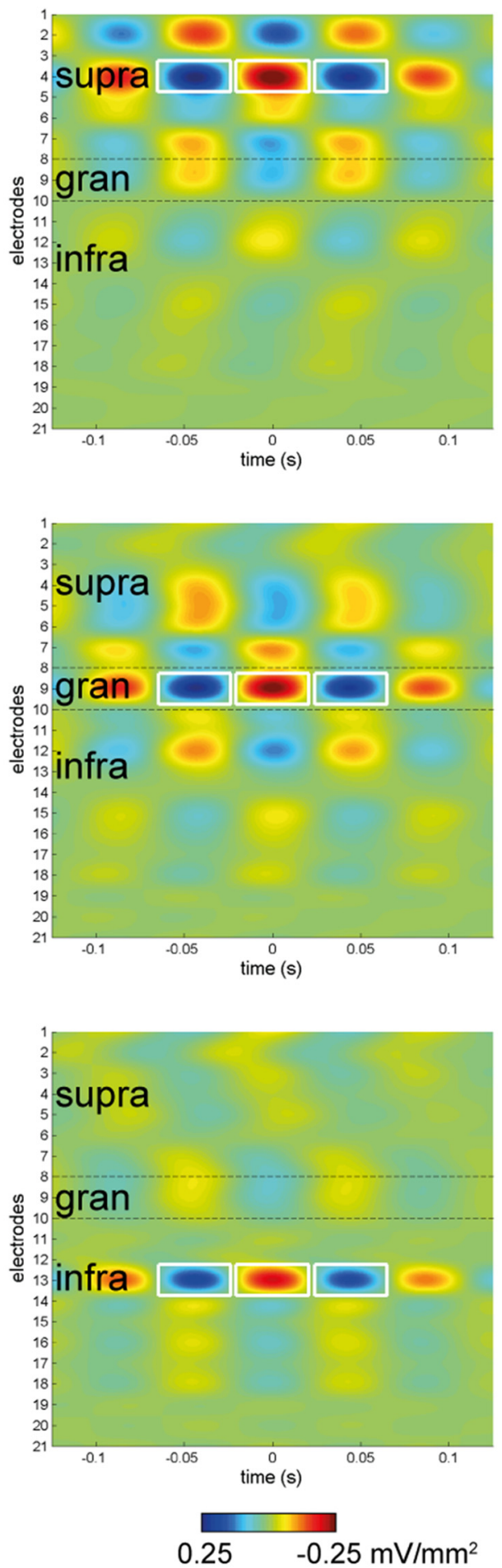

B
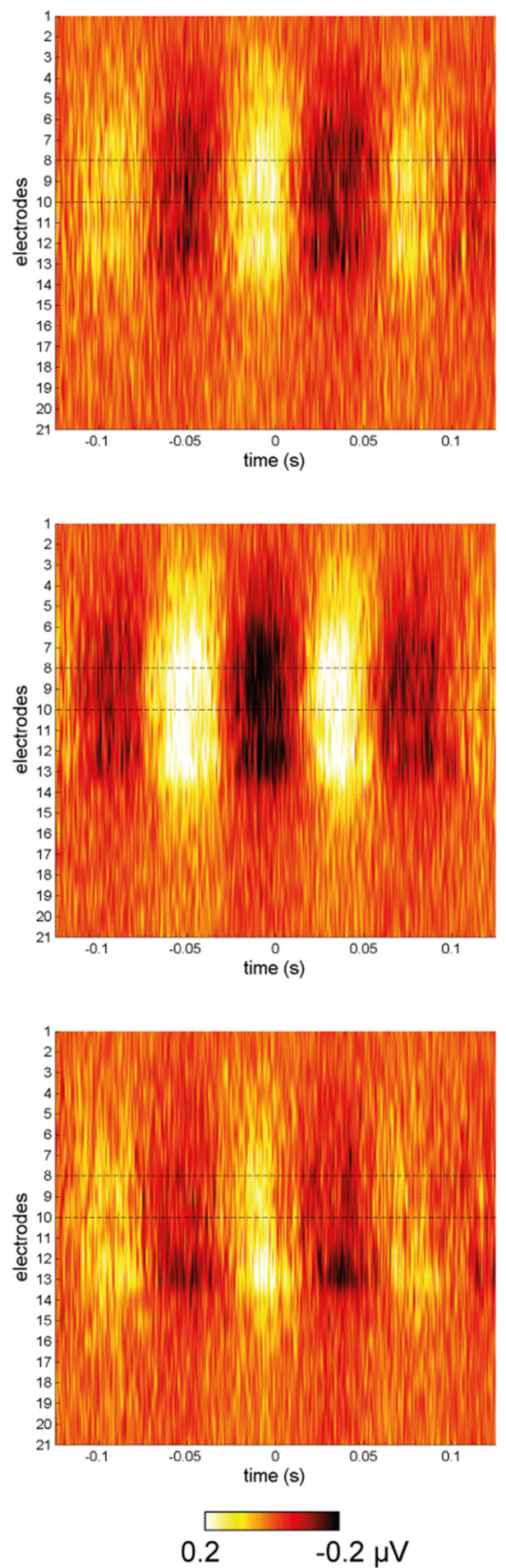

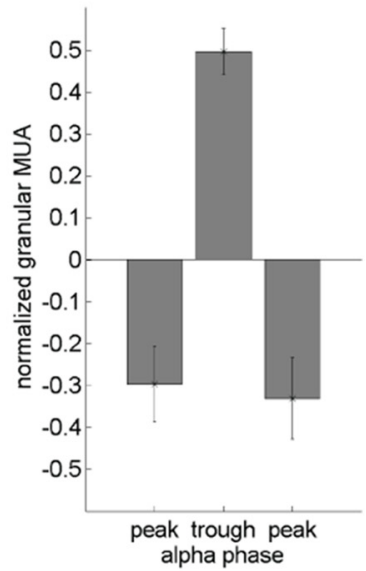

C

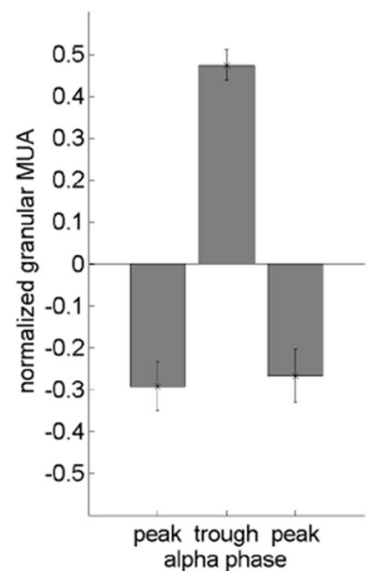

alpha phase

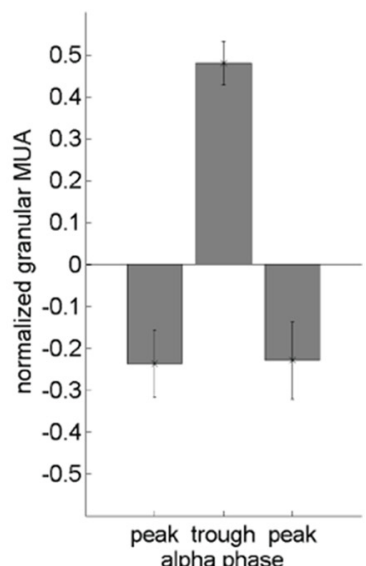

alpha phase

Figure 3. Phasic modulation of multiunit activity. $A$, Phase-realigned (SD, locked to the supragranular (supra; top), granular (gran; middle), and infragranular (infra; bottom) $\alpha$ oscillation, respectively. Data shown are for one representative recording site in S1. Time point $t=0$ reflects the peak of the $\alpha$ current sink, in the layer of interest. $\boldsymbol{B}$, Corresponding laminar MUA profiles, phase-locked to the CSD $\alpha$ cycle as indicated in A. C, Bar graphs showing phasic modulation of MUA by the $\alpha$ cycle, averaged over all recording sites in $S 1$ ( $n=29)$. The bars quantify the concurrent absolute modulation of granular MUA (relative to average MUA in that pass) for each of the $\alpha$ "hot spots" as marked in the example pass in $\boldsymbol{A}$. (Note that although $\boldsymbol{A}$ and $\boldsymbol{B}$ show plots from one example recording site, ( reflects the grand average over all penetrations.)

including one to two channels per layer as previously identified based on the evoked response (see Materials and Methods and Fig. 1), and quantified these spectra across experiments. This was done separately for the LFP signal to allow direct methodological comparison with previous studies (Buffalo et al., 2011; Bol- limunta et al., 2011; Spaak et al., 2012) and for the CSD signal to provide more accurate localization of the underlying membrane currents that generate $\alpha$ band oscillations.

We first computed the spectra for $\mathrm{V} 1$, for ongoing activity and for the "ignored" visual stimulation condition (Fig. 4). In accor- 
A

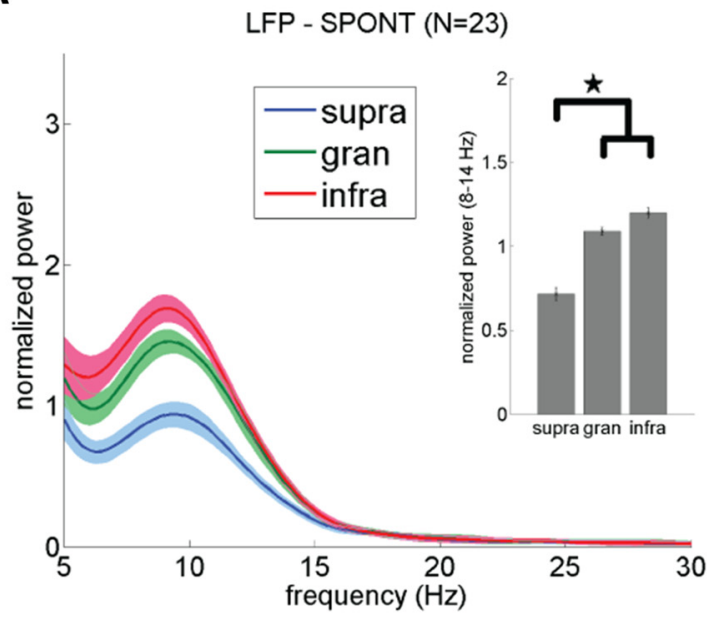

LFP - STIM $(\mathrm{N}=24)$

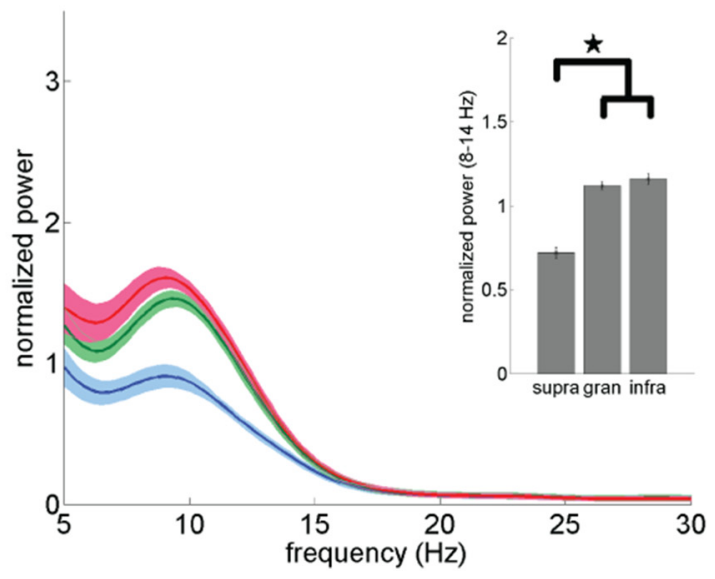

B

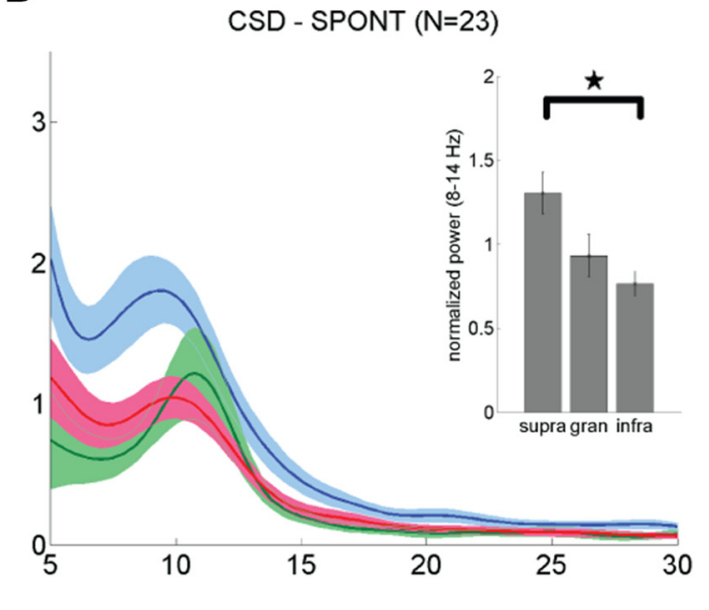

CSD - STIM $(\mathrm{N}=24)$

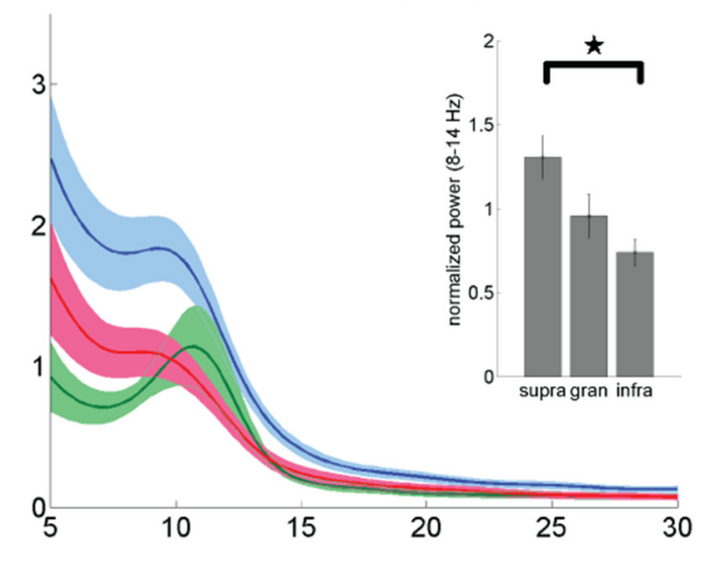

Figure 4. Laminar distribution of $\alpha$ in V1. A, Power spectra per layer [blue, supragranular (supra); green, granular (gran); red, infragranular (infra); shaded area showing SEM] based on LFP during spontaneous activity (top; averaged over 2 monkeys, $n=23$ sites) and unattended visual stimulation (bottom; prestimulus window, averaged over 2 monkeys, $n=24$ sites). Shown are spectra for the $10 \%$ highest versus $10 \%$ lowest $\alpha$ power trials. Inset, Bar graphs show $\alpha$ power $(8-14 \mathrm{~Hz})$ per layer, averaged over all trials (i.e., not just the $10 \%$ ones, normalization was solely used for visualization purposes for the spectra to reduce the $1 / f$ effect), indicating significant differences between layers with an asterisk (one-way ANOVA and subsequent Bonferroni-corrected post hoc tests, $p<0.05)$. B, Same for CSD.

dance with previous reports on visual cortex, we found that in the LFP profiles, $\alpha$ activity was strongest in the infragranular layers $\left(\right.$ SPONT: $F_{(2,66)}=65.79, p<0.001$; STIM: $F_{(2,69)}=63.65, p<$ 0.001 ; see Fig. $4 A$, insets, for significant post hoc paired comparisons, Bonferroni-corrected $p<0.05)$. However, spectral analysis of the CSD profiles yields a markedly different picture. Whereas the most prominent $\alpha(\sim 11 \mathrm{~Hz})$ "bump" appears in the granular layer spectra for both spontaneous and stimulation conditions, throughout the $8-14 \mathrm{~Hz}$ range analyzed across all penetrations, the CSD $\alpha$ power was greatest in the supragranular layers and weakest in the infragranular layers (SPONT: $F_{(2,66)}=6.34, p<$ 0.01; STIM: $F_{(2,69)}=6.38, p<0.01$; Fig. $\left.4 B\right)$.

We then repeated this analysis for S1 (Fig. 5) to determine whether this is a general property of LFP versus CSD patterns and not specific to the visual system. The S1 data (both spontaneous activity and passive contralateral somatosensory stimulation) confirmed our findings in V1: for LFP measures, $\alpha$ power was strongest in infragranular layers (SPONT: $F_{(2,84)}=5.60, p<0.01$; STIM: $F_{(2,105)}=26.54, p<0.001$; see Fig. $5 A$, insets for significant post hoc paired comparisons, Bonferroni-corrected $p<0.05$ ), whereas for CSD measures, power over the $\alpha$ range was strongest in supragranular layers $\left(\right.$ SPONT: $F_{(2,84)}=28.41, p<0.001$; STIM: $F_{(2,105)}=44.23$, $p<0.001$; Fig. $5 B)$.
The corresponding analysis for A1 (Fig. 6) yielded the same patterns of outcome: for LFP signals, $\alpha$ was strongest in infragranular layers $\left(\right.$ SPONT: $F_{(2,54)}=33.87, p<0.001$; $\operatorname{STIM}: F_{(2,54)}=39.19, p<$ 0.001 ; see Fig. $6 A$, insets for significant post hoc paired comparisons, Bonferroni-corrected $p<0.05$ ), whereas for CSD signals, $\alpha$ was strongest in supragranular layers (SPONT: $F_{(2,54)}=5.71, p<0.01$; STIM: $F_{(2,54)}=6.42, p<0.01$; Fig. $\left.6 B\right)$. Thus, for all three primary sensory cortices, we found that when analyzing LFP spectra, $\alpha$ power was strongest in infragranular layers, whereas the spectral analysis of CSD profiles indicated strongest $\alpha$ generators in the supragranular layers.

\section{A caveat: influence of reference location}

To investigate to what extent these LFP versus CSD differences could be explained by the fact that the LFP was recorded against a common reference (and not rereferenced), we computed the same profiles using bipolar derivation (i.e., first spatial derivative). The bipolar derivation gave results similar to CSD analysis for all three areas (Fig. 7). We observed these patterns during both spontaneous activity and passive stimulation (V1, SPONT: $F_{(2,66)}=32.83, p<0.001$; STIM: $F_{(2,69)}=36.45, p<0.001 ; \mathrm{S} 1$, SPONT: $F_{(2,84)}=27.18, p<0.001$; STIM: $F_{(2,105)}=43.93, p<$ 
A

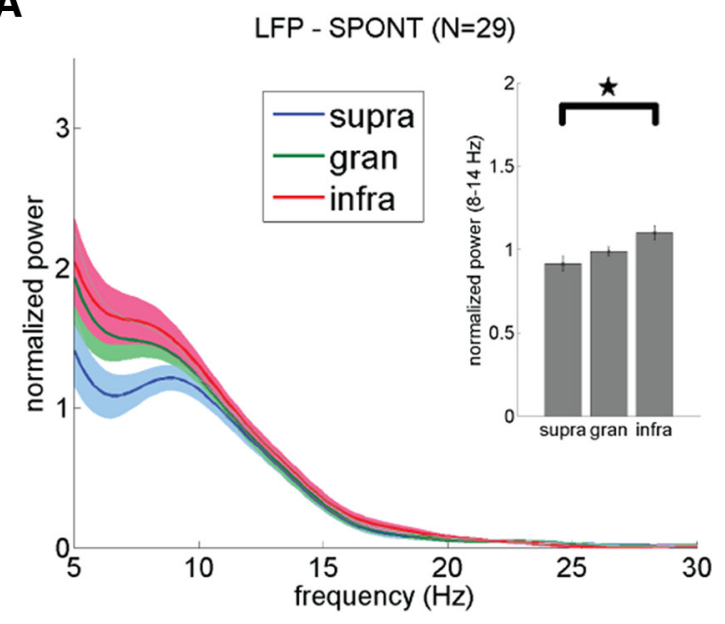

LFP - STIM (N=36)

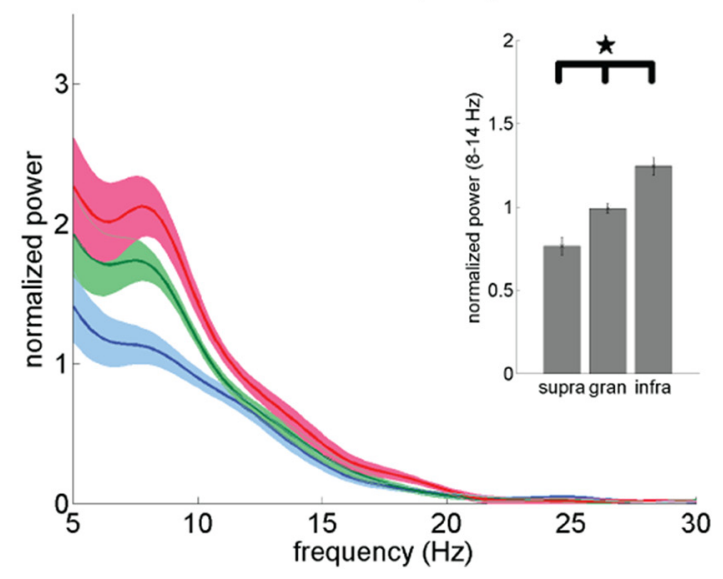

B

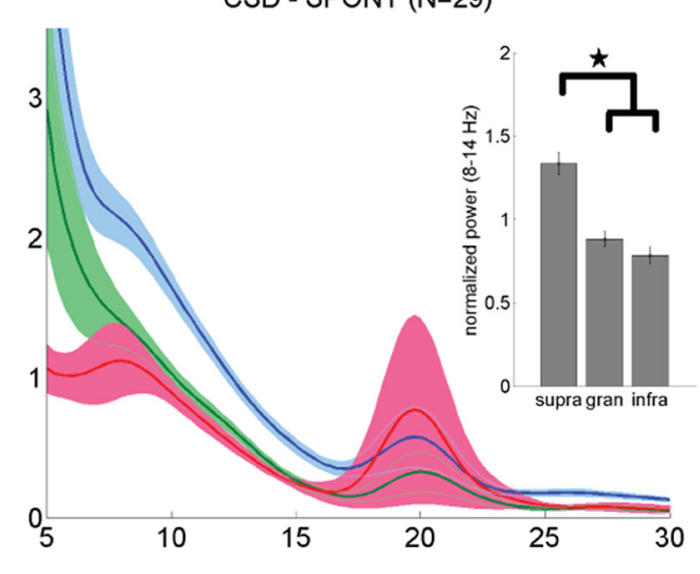

CSD - STIM $(\mathrm{N}=36)$

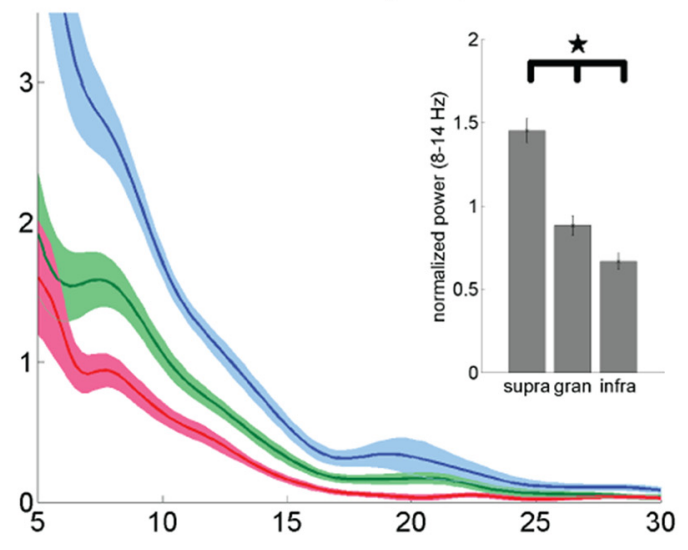

Figure 5. Laminar distribution of $\alpha$ inS1.A, Power spectra per layer [blue, supragranular (supra); green, granular (gran); red, infragranular (infra); shaded area showing SEM] based on LFP during spontaneous activity (top; averaged over 3 monkeys, $n=29$ sites) and passive contralateral stimulation (bottom; prestimulus window, averaged over 3 monkeys, $n=36$ sites). Shown are spectra for the $10 \%$ highest versus $10 \%$ lowest $\alpha$ power trials. Inset, Bar graphs show $\alpha$ power $(8-14 \mathrm{~Hz})$ per layer, averaged over all trials (i.e., not just the $10 \%$ ones), indicating significant differences between layers with an asterisk (one-way ANOVA and subsequent Bonferroni-corrected post hoc tests, $p<0.05$ ). $\boldsymbol{B}$, Same for CSD.

0.001 ; A1, SPONT: $F_{(2,54)}=36.82, p<0.001 ;$ STIM: $F_{(2,54)}=$ 38.51, $p<0.001)$.

Given the powerful effects of volume conduction in referential recordings (Kajikawa and Schroeder, 2011), as an additional test, we explored how the location of the reference site (used for differential amplification) influences the LFP during two V1 experiments in one monkey. This was done to determine whether reference location might contribute to the discrepancy between LFP and CSD estimates of the laminar amplitude distribution. We used three reference locations: frontal scalp midline, opposite-side V1 recording chamber, and same-side V1 chamber. The rationale is that while the CSD is unaffected by reference site (since all reference activity is subtracted out by the derivation), choice of reference sites that are effectively above (ipsilateral V1 chamber) or below (frontal scalp and contralateral V1) the recording site might dramatically shift the laminar amplitude profile of $\alpha$ LFP activity. We found that reference location has substantial effects on the LFP spectra, not just in power levels but also in peak frequencies, while the CSD remains unaffected (Fig. 8; note that minor shifts in CSD peaks can be explained by the fact that the different referencing conditions were recorded at slightly different moments in time). Despite these effects, however, infragranular LFP signals remain larger than granular and supragranular ones, and thus reference location does not appear to account for the relative differences in laminar amplitude distribution derived from CSD versus LFP signals.

\section{Discussion}

By any measure, $\alpha$ oscillations are found in all cortical layers. When strictly localized using CSD analysis, $\alpha$ current generators were found in the supragranular, granular, and infragranular layers and were related to phasic modulation of excitability as indexed by fluctuations in local neuronal firing (MUA). The latter confirmed previous findings (Haegens et al., 2011b; van Kerkoerle et al., 2014), here localized predominantly to granular and deeper layers.

Based on CSD analysis, $\alpha$ generators were strongest in the supragranular layers, whereas based on LFP signals, $\alpha$ power was strongest in the infragranular layers. This was true in V1, S1, and A1 during both spontaneous activity and passive sensory stimulation. The larger $\alpha$ LFP power in infragranular layers is consistent with previous reports in visual cortex (Maier et al., 2010, 2011; Buffalo et al., 2011; Spaak et al., 2012; van Kerkoerle et al., 2014). An obvious explanation for this discrepancy between LFP and CSD is contamination of the infragranular LFP signal by activity that is volume-conducted from the stronger supragranular generators (Kajikawa and Schroeder, 2011, 2015). 
A

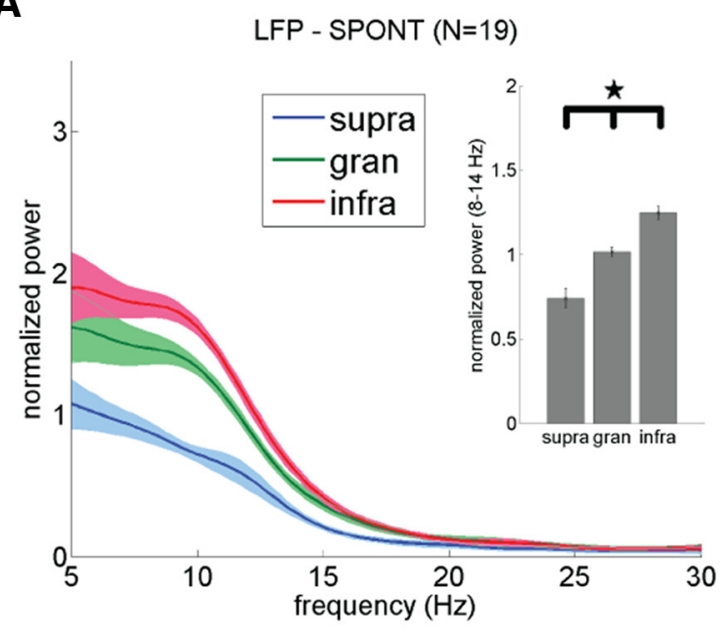

LFP - STIM $(\mathrm{N}=19)$

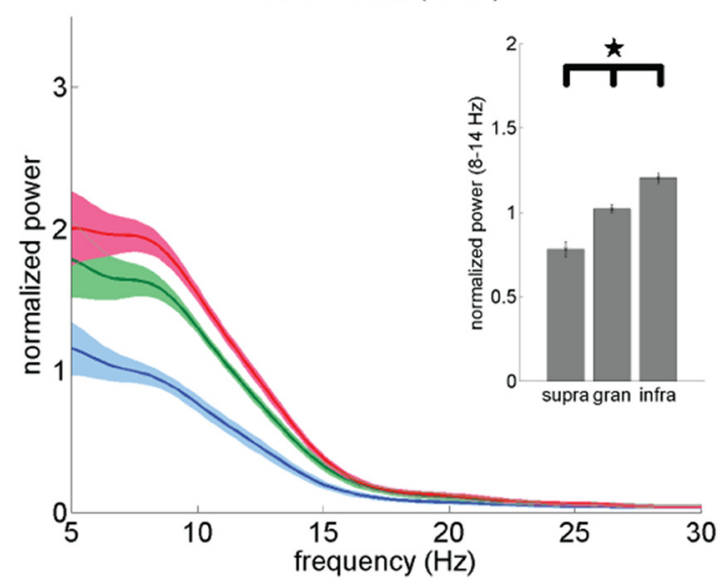

B

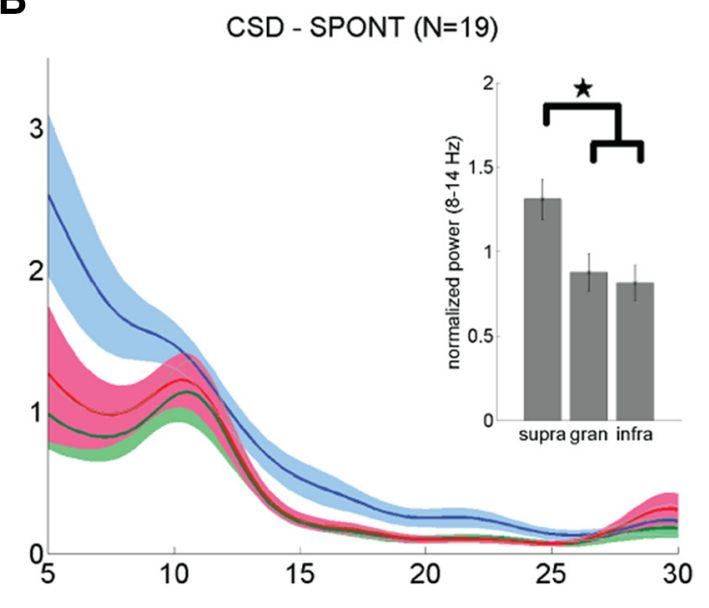

CSD - STIM $(\mathrm{N}=19)$

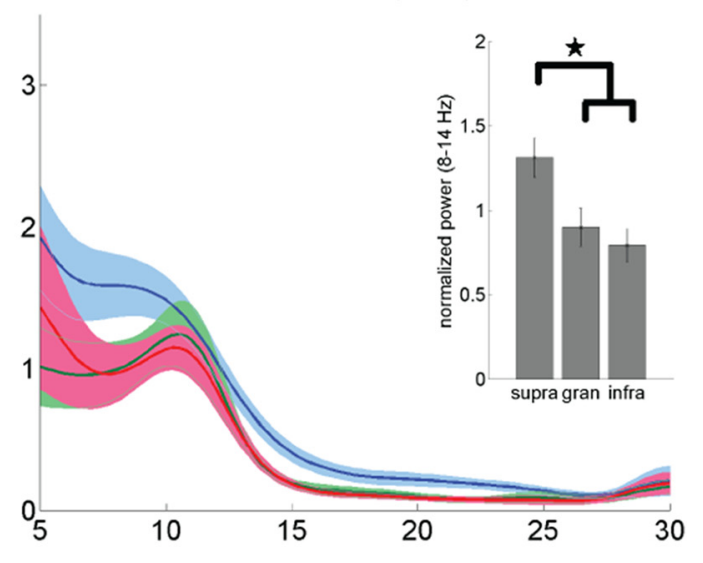

Figure 6. Laminar distribution of $\alpha$ in A1.A, Power spectra per layer [blue, supragranular (supra); green, granular (gran); red, infragranular (infra); shaded area showing SEM] based on LFP during spontaneous activity (top; averaged over 3 monkeys, $n=19$ sites) and unattended auditory stimulation (bottom; prestimulus window, averaged over 3 monkeys, $n=19$ sites). Shown are spectra for the $10 \%$ highest versus $10 \%$ lowest $\alpha$ power trials. Inset, Bar graphs show $\alpha$ power $(8-14 \mathrm{~Hz})$ per layer, averaged over all trials (i.e., not just the $10 \%$ ones), indicating significant differences between layers with an asterisk (one-way ANOVA and subsequent Bonferroni-corrected post hoc tests, $p<0.05$ ). B, Same for CSD.

In that light, note that Buffalo et al. (2011) used single microelectrodes to record the LFP at different depths, rather than first (bipolar) or second (CSD) derivative approximation. Maier et al. (2010) analyzed the raw LFP as recorded with laminar probes with the electrode shank as reference. Spaak et al. (2012) analyzed this same dataset, using a bipolar derivation to circumvent the before-mentioned reference issues. Although showing a very interesting interlaminar cross-frequency coupling between $\alpha$ phase in deep layers and $\gamma$ amplitude in granular and superficial layers, their approach does not allow conclusions on the locus of $\alpha$ generation, as the analysis targeted high infragranular $\alpha$ power trials to begin with.

Van Kerkoerle et al. (2014) also found strongest $\alpha$ power in the deep layers, based on the LFP signal. However, based on CSD and MUA analysis, they found that $\alpha$ originates in both the supragranular and infragranular layers and propagates from there to the granular layer. This is not necessarily conflicting with our findings, as we find $\alpha$ sources across all laminae. These authors reported a feedback role for $\alpha$ (while $\gamma$ oscillations fulfill the feedforward operation). Here, we did not observe specific feedforward versus feedback patterns; however, the fact that we only looked at resting/passive conditions whereas van Kerkoerle et al. (2014) limited their analysis to an active task condition may (partly) explain this discrepancy.

\section{Reference location influences LFP spectra}

A critical concern regarding the LFP is that precise localization of the signal origin is difficult because of the use of distant, extracranial reference electrodes (Kajikawa and Schroeder, 2011). Since these reference electrodes are unlikely to be "silent," measures such as common average rereferencing, bipolar derivation, or CSD computation are often used to subtract out the reference activity (Nicholson and Freeman, 1975; Mitzdorf, 1985; Kajikawa and Schroeder, 2011). In our experiments, the power spectrum of the "raw" LFP is dependent on reference location, to such extent that spectral peaks shift, not just in absolute power but also in peak frequency. The important point, however, is that with a distant reference site, it is impossible to distinguish reference-site influences and volume-conducted signal (see below) from the actual local activations. Consequently, in lieu of a method to manage reference effects, spectral modulations cannot be accurately ascribed to the location in which LFPs have been recorded.

\section{Volume conduction and laminar localization of $\boldsymbol{\alpha}$}

The CSD profile reflects local transmembrane current flow, with global signals, including volume-conducted activity, subtracted out (Nicholson, 1973; Nicholson and Freeman, 1975; Mitzdorf, 1985; Kajikawa and Schroeder, 2011). The LFP signal in contrast, 
A

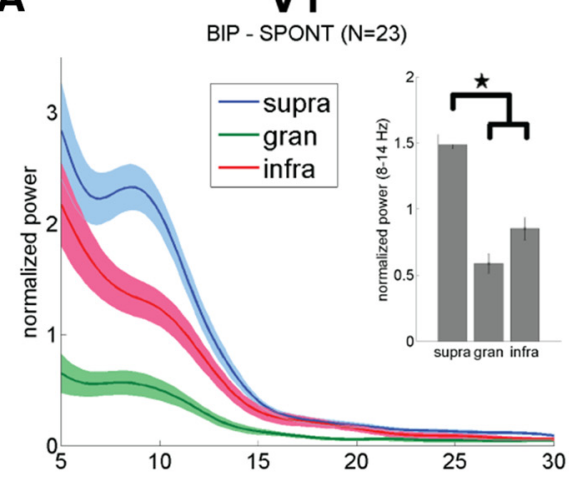

B

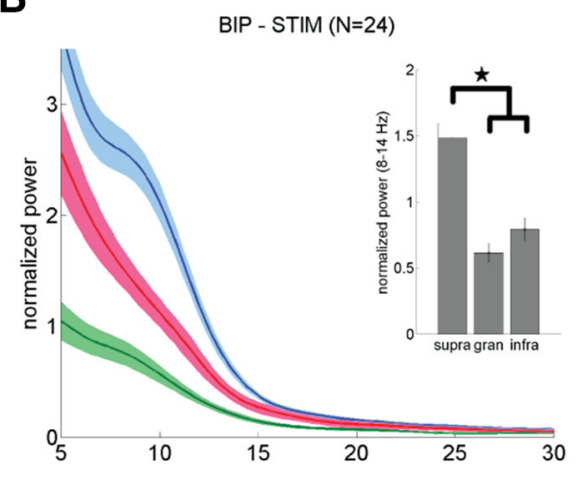

S1

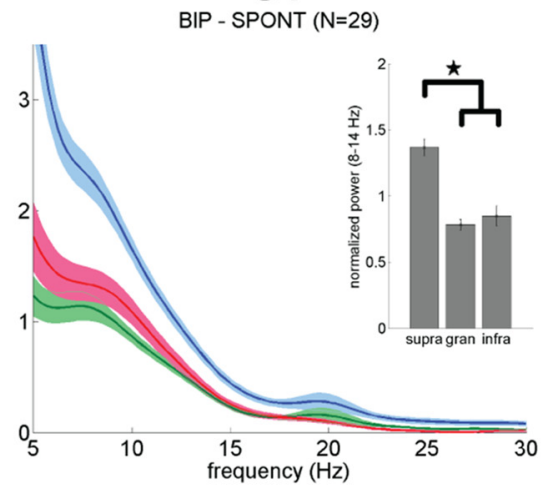

BIP - STIM (N=36)

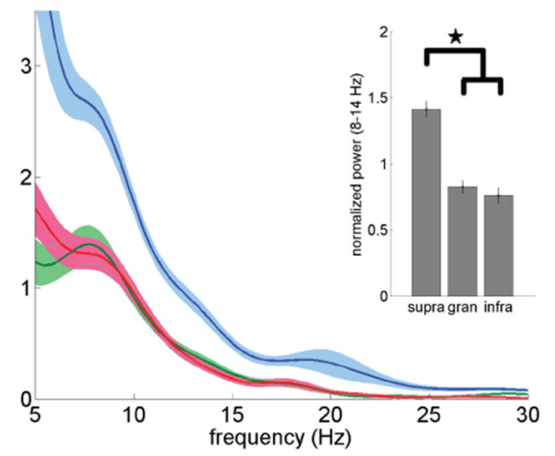

A1

BIP - SPONT ( $=19)$

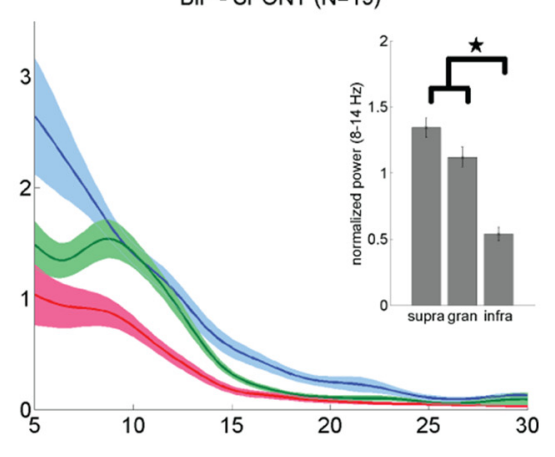

BIP - STIM (N=19)

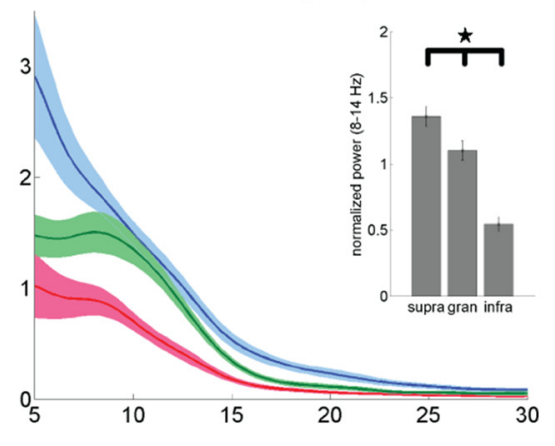

Figure 7. Laminar distribution of $\alpha$-bipolar derivation. A, Power spectra per layer [blue, supragranular (supra); green, granular (gran); red, infragranular (infra); shaded area showing SEM] for bipolar derivation in V1 (left), S1 (middle), and A1 (right). Shown are spectra for the 10\% highest versus 10\% lowest $\alpha$ power trials during spontaneous activity. Inset, Bar graphs show $\alpha$ power $(8-14 \mathrm{~Hz}$ ) per layer, averaged over all trials (i.e., not just the $10 \%$ ones), indicating significant differences between layers with an asterisk (one-way ANOVA and subsequent Bonferroni-corrected post hoc tests, $p<0.05)$. B, Same for passive stimulation conditions.

is very sensitive to volume conduction, and any given channel may contain activity from neighboring layers and more distant cortical (Kajikawa and Schroeder, 2011,2015) or even subcortical (Schroeder et al., 1992) sources. Credible estimates of the distance over which volume conduction can occur range from the order of millimeters (Kreiman et al., 2006; Berens et al., 2008; Nauhaus et al., 2009) to distances an order of magnitude greater (Schroeder et al., 1992; Kajikawa and Schroeder, 2011). The fact that CSD signals localize the strongest $\alpha$ generators in the supragranular layers, while LFP signals localize them in the infragranular layers, argues strongly that the latter reflect both local signals and contamination by volume conduction. Recent modeling work has indeed shown that with weak local generators, susceptibility to volume conduction effects over distance increases, making the infragranular LFP the most susceptible to contributions from other layers (Kajikawa and Schroeder, 2015). The most likely sources of contamination are strong LFP generators in the supragranular layers. Although there are other potential sources of volume-conducted signals including the thalamus, our rereferencing experiments in V1 provide no clear support for a thalamic source or more rostral cortical source, as none of the alternate reference positions reversed the laminar amplitude distributions derived from monopolar LFP recordings.

\section{Laminar organization and cellular generators}

Layer 5 pyramidal cells have been proposed as cortical pacemakers and generators for the $\alpha$ rhythm, receiving inhibitory feedback from GABAergic interneurons (Steriade et al., 1990; Jones et al., 2000), and/or driven by excitatory input (Sun and Dan, 2009). Computational modeling by Jones et al. (2009) showed that layer 5 pyramidal cells can produce an $\alpha$ oscillation along the apical dendrite, by receiving $\sim 10-\mathrm{Hz}$ stochastic inputs at two different laminar locations - cortical feedback and non-specific thalamic inputs to distal apical dendrites in the supragranular layers, and feedforward (thalamic) inputs via layer 4 to layer 5 basal dendrites (cf. Douglas and Martin, 2004; Spruston, 2008).

In light of the Jones model, our observation of strong $\alpha$ generators in the supragranular layers may reflect synaptic inputs on the apical dendrites of layer 5 pyramidal cells, while the (weaker) infragranular $\alpha$ generators could reflect basal dendritic synaptic inputs. However, it is worth considering the alternatives, e.g., the obvious possibility that supragranular layer pyramidal cells are also involved in $\alpha$ generation. These have by far the most numerous synaptic contacts in the supragranular layers (DeFelipe and Fariñas, 1992; Oberlaender et al., 2011), and whereas supragranular responses typically are synchronized with infragranular responses, they can be dissociated (e.g., pharmacological manipulations; Schroeder et al., 1990, 1997). Finally, previous Granger causality studies suggest that supragranular and infragranular sites, along with thalamic inputs, may play differing pace-making roles in cortical $\alpha$ generation (Bollimunta et al., 2008, 2011).

Another model places thalamically driven cortical $\alpha$ in the supragranular layers (Vijayan and Kopell, 2012), based on a more explicit drive from LGN (Hughes et al., 2004; Lörincz et al., 2008) and the empirical finding that supragranular and thalamic $\alpha$ are generally synchronized (Bollimunta et al., 2011). Though we did not formally analyze $\alpha$ coherence across layers here, our findings are consistent with supra-infragranular $\alpha$ synchrony (Fig. 3). Our CSD-based findings do not, at this point, distinguish between the Jones and the Vijayan and Kopell models. Whereas our conclu- 
A
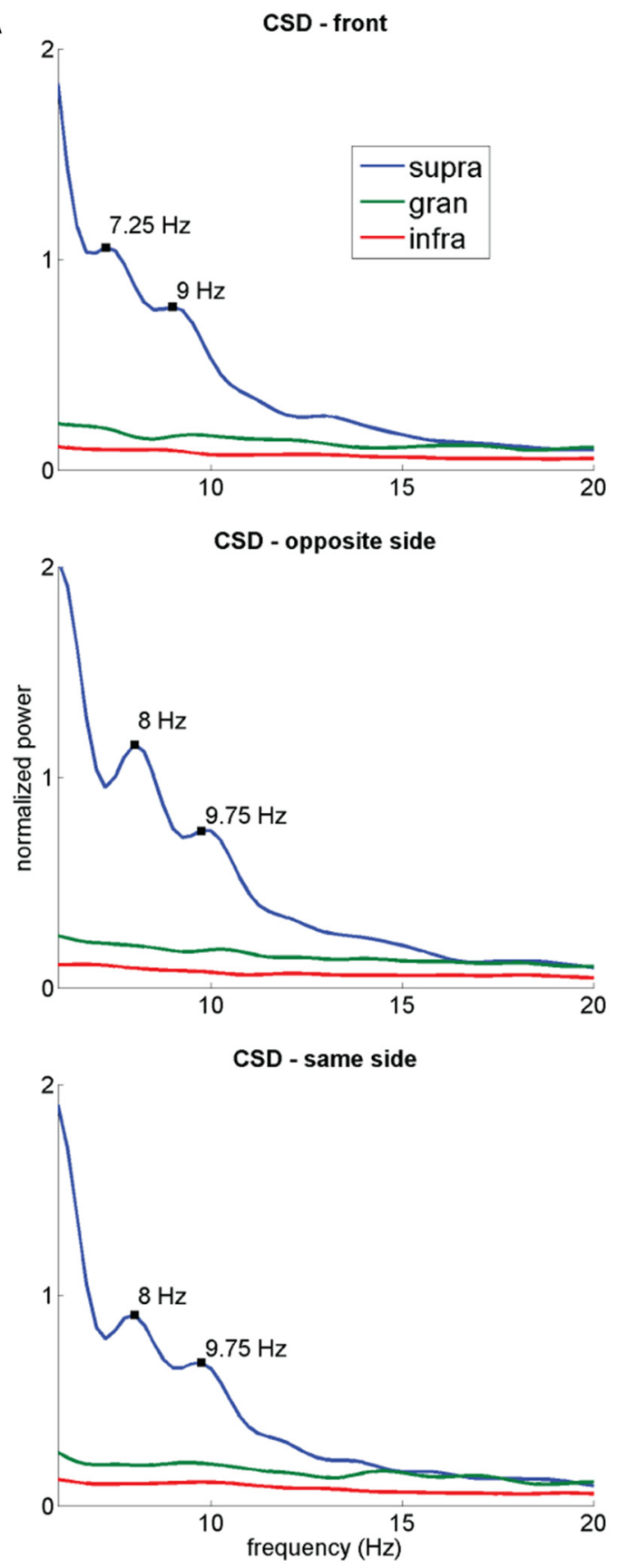

B

LFP - front
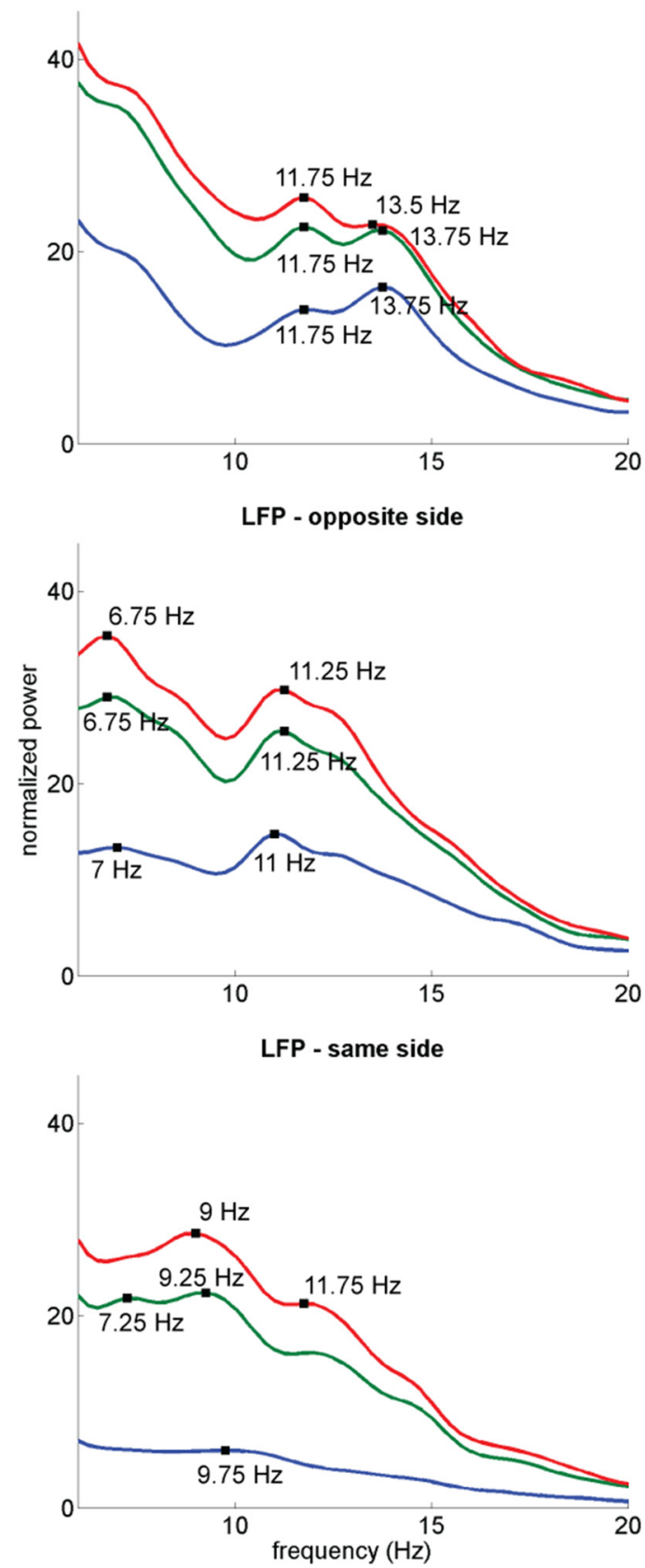

Figure 8. Influence of reference location. A, Power spectra per layer [blue, supragranular (supra); green, granular (gran); red, infragranular (infra)] for CSD, averaged over two recording sessions in one monkey using different reference locations (top, front of head center; middle, contralateral V1; bottom, ipsilateral V1). Local maxima are marked in the plot. B, Same for LFP. Notice the strong influence of reference location on spectral peaks here.

sions are in disagreement with those of previous reports (Buffalo et al., 2011; Spaak et al., 2012), which concluded a predominantly infragranular source of the $\alpha$ rhythm, we think this can be explained by a bias introduced by the LFP approach.

\section{Conclusion}

The laminar distribution of $\alpha$ band activity appears more complex than generally assumed. Our findings do not replace the " $\alpha$ comes from deeper layers" view with a claim that $\alpha$ is exclusively generated in superficial layers. A mass of evidence now indicates that $\alpha$ field potential generators can be observed in each of the laminae, with an intricate modulation/drive by other (higherorder) cortical areas and several thalamic nuclei. Our findings do not distinguish between the "sensory inhibition" and "sampling rate/parsing" views of $\alpha$ functioning. However, the fact that $\alpha$ is generated and modulates cellular excitability locally within supragranular as well as infragranular layers indicates that $\alpha$ is likely involved in feedforward, as well as feedback, processes. It seems likely that layer 5 pyramidal cells play a crucial role in $\alpha$ generation, and it is important to keep in mind the cytoarchitecture here: dendrites of these pyramidal cells span across laminae, with the apical dendrites reaching far into supragranular layers and various cell types providing distinct synaptic inputs (Spruston, 2008; Oberlaender et al., 2011). However, given the present findings and previous reports (Bollimunta et al., 2008, 2011), participation by supragranular pyramidal neurons likely plays a 
consequential role. Mapping these various mechanistic contributions and their role in $\alpha$ generation will be key in understanding the role of $\alpha$ in brain operation.

\section{References}

Banerjee S, Snyder AC, Molholm S, Foxe JJ (2011) Oscillatory $\alpha$-band mechanisms and the deployment of spatial attention to anticipated auditory and visual target locations: supramodal or sensory-specific control mechanisms? J Neurosci 31:9923-9932. CrossRef Medline

Barna JS, Arezzo JC, Vaughan HG Jr (1981) A new multielectrode array for the simultaneous recording of field potentials and unit activity. Electroencephalogr Clin Neurophysiol 52:494-496. CrossRef Medline

Başar E (2012) A review of alpha activity in integrative brain function: fundamental physiology, sensory coding, cognition and pathology. Int J Psychophysiol 86:1-24. CrossRef Medline

Berens P, Keliris GA, Ecker AS, Logothetis NK, Tolias AS (2008) Comparing the feature selectivity of the gamma-band of the local field potential and the underlying spiking activity in primate visual cortex. Front Syst Neurosci 2:199-207. CrossRef Medline

Bollimunta A, Chen Y, Schroeder CE, Ding M (2008) Neuronal mechanisms of cortical $\alpha$ oscillations in awake-behaving macaques. J Neurosci 28:9976-9988. CrossRef Medline

Bollimunta A, Mo J, Schroeder CE, Ding M (2011) Neuronal mechanisms and attentional modulation of corticothalamic $\alpha$ oscillations. J Neurosci 31:4935-4943. CrossRef Medline

Buffalo EA, Fries P, Landman R, Buschman TJ, Desimone R (2011) Laminar differences in gamma and alpha coherence in the ventral stream. Proc Natl Acad Sci U S A 108:11262-11267. CrossRef Medline

Busch NA, Dubois J, VanRullen R (2009) The phase of ongoing EEG oscillations predicts visual perception. J Neurosci 29:7869-7876. CrossRef Medline

DeFelipe J, Fariñas I (1992) The pyramidal neuron of the cerebral cortex: morphological and chemical characteristics of the synaptic inputs. Prog Neurobiol 39:563-607. CrossRef Medline

Douglas RJ, Martin KA (2004) Neuronal circuits of the neocortex. Annu Rev Neurosci 27:419-451. CrossRef Medline

Dugué L, Marque P, VanRullen R (2011) The phase of ongoing oscillations mediates the causal relation between brain excitation and visual perception. J Neurosci 31:11889-11893. CrossRef Medline

Foxe JJ, Snyder AC (2011) The role of alpha-band brain oscillations as a sensory suppression mechanism during selective attention. Front Psychol 2:154. CrossRef

Gould IC, Rushworth MF, Nobre AC (2011) Indexing the graded allocation of visuospatial attention using anticipatory alpha oscillations. J Neurophysiol 105:1318-1326. CrossRef Medline

Haegens S, Osipova D, Oostenveld R, Jensen O (2010) Somatosensory working memory performance in humans depends on both engagement and disengagement of regions in a distributed network. Hum Brain Mapp 31:26-35. CrossRef Medline

Haegens S, Händel BF, Jensen O (2011a) Top-down controlled $\alpha$ band activity in somatosensory areas determines behavioral performance in a discrimination task. J Neurosci 31:5197-5204. CrossRef Medline

Haegens S, Nácher V, Luna R, Romo R, Jensen O (2011b) $\alpha$-Oscillations in the monkey sensorimotor network influence discrimination performance by rhythmical inhibition of neuronal spiking. Proc Natl Acad Sci U S A 108:19377-19382. CrossRef Medline

Haegens S, Vázquez Y, Zainos A, Alvarez M, Jensen O, Romo R (2014) Thalamocortical rhythms during a vibrotactile detection task. Proc Natl Acad Sci U S A 111:E1797-E1805. CrossRef Medline

Hughes SW, Lörincz M, Cope DW, Blethyn KL, Kékesi KA, Parri HR, Juhász G, Crunelli V (2004) Synchronized oscillations at $\alpha$ and $\theta$ frequencies in the lateral geniculate nucleus. Neuron 42:253-268. CrossRef Medline

Jensen O, Mazaheri A (2010) Shaping functional architecture by oscillatory alpha activity: gating by inhibition. Front Hum Neurosci 4:186. CrossRef Medline

Jones SR, Pinto DJ, Kaper TJ, Kopell N (2000) Alpha-frequency rhythms desynchronize over long cortical distances: a modeling study. J Comput Neurosci 9:271-291. CrossRef Medline

Jones SR, Pritchett DL, Sikora MA, Stufflebeam SM, Hämäläinen M, Moore CI (2009) Quantitative analysis and biophysically realistic neural modeling of the MEG mu rhythm: rhythmogenesis and modulation of sensory-evoked responses. J Neurophysiol 102:3554-3572. CrossRef Medline

Kaiser J, Heidegger T, Wibral M, Altmann CF, Lutzenberger W (2007) Alpha synchronization during auditory spatial short-term memory. Neuroreport 18:1129-1132. CrossRef Medline

Kajikawa Y, Schroeder CE (2011) How local is the local field potential? Neuron 72:847-858. CrossRef Medline

Kajikawa Y, Schroeder CE (2015) Generation of field potentials and modulation of their dynamics through volume integration of cortical activity. J Neurophysiol 113:339-351. CrossRef Medline

Klimesch W (1999) EEG alpha and theta oscillations reflect cognitive and memory performance: a review and analysis. Brain Res Rev 29:169-195. CrossRef Medline

Klimesch W, Sauseng P, Hanslmayr S (2007) EEG alpha oscillations: the inhibition-timing hypothesis. Brain Res Rev 53:63-88. CrossRef Medline

Kreiman G, Hung CP, Kraskov A, Quiroga RQ, Poggio T, DiCarlo JJ (2006) Object selectivity of local field potentials and spikes in the macaque inferior temporal cortex. Neuron 49:433-445. CrossRef Medline

Lakatos P, Karmos G, Mehta AD, Ulbert I, Schroeder CE (2008) Entrainment of neuronal oscillations as a mechanism of attentional selection. Science 320:110-113. CrossRef Medline

Lakatos P, O'Connell MN, Barczak A, Mills A, Javitt DC, Schroeder CE (2009) The leading sense: supramodal control of neurophysiological context by attention. Neuron 64:419-430. CrossRef Medline

Lakatos P, Musacchia G, O'Connel MN, Falchier AY, Javitt DC, Schroeder CE (2013) The spectrotemporal filter mechanism of auditory selective attention. Neuron 77:750-761. CrossRef Medline

Lipton ML, Fu KM, Branch CA, Schroeder CE (2006) Ipsilateral hand input to area $3 \mathrm{~b}$ revealed by converging hemodynamic and electrophysiological analyses in macaque monkeys. J Neurosci 26:180-185. CrossRef Medline

Lipton ML, Liszewski MC, O'Connell MN, Mills A, Smiley JF, Branch CA, Isler JR, Schroeder CE (2010) Interactions within the hand representation in primary somatosensory cortex of primates. J Neurosci 30:1589515903. CrossRef Medline

Lopes da Silva F (1991) Neural mechanisms underlying brain waves: from neural membranes to networks. Electroencephalogr Clin Neurophysiol 79:81-93. CrossRef Medline

Lörincz ML, Crunelli V, Hughes SW (2008) Cellular dynamics of cholinergically induced $\alpha(8-13 \mathrm{~Hz})$ rhythms in sensory thalamic nuclei in vitro. J Neurosci 28:660-671. CrossRef Medline

Lund JS (1988) Anatomical organization of macaque monkey striate cortex. Annu Rev Neurosci 11:253-288. CrossRef Medline

Luo H, Poeppel D (2007) Phase patterns of neuronal responses reliably discriminate speech in human auditory cortex. Neuron 54:1001-1010. CrossRef Medline

Maier A, Adams GK, Aura C, Leopold DA (2010) Distinct superficial and deep laminar domains of activity in the visual cortex during rest and stimulation. Front Syst Neurosci 4:pii:31. CrossRef Medline

Maier A, Aura CJ, Leopold DA (2011) Infragranular sources of sustained local field potential responses in macaque primary visual cortex. J Neurosci 31:1971-1980. CrossRef Medline

Mehta AD, Ulbert I, Schroeder CE (2000) Intermodal selective attention in monkeys. I: Distribution and timing of effects across visual areas. Cereb Cortex 10:343-358. CrossRef Medline

Mitzdorf U (1985) Current source-density method and application in cat cerebral cortex: investigation of evoked potentials and EEG phenomena. Physiol Rev 65:37-100. Medline

Mo J, Schroeder CE, Ding M (2011) Attentional modulation of $\alpha$ oscillations in macaque inferotemporal cortex. J Neurosci 31:878-882. CrossRef Medline

Nauhaus I, Busse L, Carandini M, Ringach DL (2009) Stimulus contrast modulates functional connectivity in visual cortex. Nat Neurosci 12:7076. CrossRef Medline

Nicholson C (1973) Theoretical analysis of field potentials in anisotropic ensembles of neuronal elements. IEEE Trans Biomed Eng BME 20:278288. Medline

Nicholson C, Freeman JA (1975) Theory of current source-density analysis and determination of conductivity tensor for anuran cerebellum. J Neurophysiol 38:356-368. Medline

Oberlaender M, de Kock CPJ, Bruno RM, Ramirez A, Meyer HS, Dercksen VJ, Helmstaedter M, Sakmann B (2011) Cell type-specific three-dimensional structure of 
thalamocortical circuits in a column of rat vibrissal cortex. Cereb Cortex 22:23752391. CrossRef Medline

Oostenveld R, Fries P, Maris E, Schoffelen J-M (2011) FieldTrip: open source software for advanced analysis of MEG, EEG, and invasive electrophysiological data. Comput Intell Neurosci 2011:156869. CrossRef Medline

Palva S, Palva JM (2007) New vistas for alpha-frequency band oscillations. Trends Neurosci 30:150-158. CrossRef Medline

Peterson NN, Schroeder CE, Arezzo JC (1995) Neural generators of early cortical somatosensory evoked potentials in the awake monkey. Electroencephalogr Clin Neurophysiol 96:248-260. CrossRef Medline

Saalmann YB, Pinsk MA, Wang L, Li X, Kastner S (2012) The pulvinar regulates information transmission between cortical areas based on attention demands. Science 337:753-756. CrossRef Medline

Schroeder CE, Tenke CE, Givre SJ, Arezzo JC, Vaughan HG Jr (1990) Laminar analysis of bicuculline-induced epileptiform activity in area 17 of the awake macaque. Brain Res 515:326-330. CrossRef Medline

Schroeder CE, Tenke CE, Givre SJ, Arezzo JC, Vaughan HG Jr (1991) Striate cortical contribution to the surface-recorded pattern-reversal VEP in the alert monkey. Vision Res 31:1143-1157. CrossRef Medline

Schroeder CE, Tenke CE, Givre SJ (1992) Subcortical contributions to the surface-recorded flash-VEP in the awake macaque. Electroencephalogr Clin Neurophysiol 84:219-231. CrossRef Medline

Schroeder CE, Javitt DC, Steinschneider M, Mehta AD, Givre SJ, Vaughan HG Jr, Arezzo JC (1997) N-methyl-D-aspartate enhancement of phasic responses in primate neocortex. Exp Brain Res 114:271-278.

Schroeder CE, Mehta AD, Givre SJ (1998) A spatiotemporal profile of visual system activation revealed by current source density analysis in the awake macaque. Cereb Cortex 8:575-592. CrossRef Medline

Schroeder CE, Lindsley RW, Specht C, Marcovici A, Smiley JF, Javitt DC (2001) Somatosensory input to auditory association cortex in the macaque monkey. J Neurophysiol 85:1322-1327. Medline

Schroeder CE, Lakatos P, Kajikawa Y, Partan S, Puce A (2008) Neuronal oscillations and visual amplification of speech. Trends Cogn Sci 12:106113. CrossRef Medline

Spaak E, Bonnefond M, Maier A, Leopold DA, Jensen O (2012) Layerspecific entrainment of gamma-band neural activity by the alpha rhythm in monkey visual cortex. Curr Biol 22:2313-2318. CrossRef Medline

Spruston N (2008) Pyramidal neurons: dendritic structure and synaptic integration. Nat Rev Neurosci 9:206-221. CrossRef Medline

Steinschneider M, Tenke CE, Schroeder CE, Javitt DC, Simpson GV, Arezzo JC, Vaughan HG Jr (1992) Cellular generators of the cortical auditory evoked potential initial component. Electroencephalogr Clin Neurophysiol 84:196-200. CrossRef Medline

Steriade M, Gloor P, Llinás RR, Lopes de Silva FH, Mesulam MM (1990) Basic mechanisms of cerebral rhythmic activities. Electroencephalogr Clin Neurophysiol 76:481-508. CrossRef Medline

Sun W, Dan Y (2009) Layer-specific network oscillation and spatiotemporal receptive field in the visual cortex. Proc Natl Acad Sci U S A 106:1798617991. CrossRef Medline

Thut G, Nietzel A, Brandt SA, Pascual-Leone A (2006) $\alpha$-Band electroencephalographic activity over occipital cortex indexes visuospatial attention bias and predicts visual target detection. J Neurosci 26:9494-9502. CrossRef Medline

Tiihonen J, Hari R, Kajola M, Karhu J, Ahlfors S, Tissari S (1991) Magnetoencephalographic $10-\mathrm{Hz}$ rhythm from the human auditory cortex. Neurosci Lett 129:303-305. CrossRef Medline

van Kerkoerle T, Self MW, Dagnino B, Gariel-Mathis MA, Poort J, van der Togt C, Roelfsema PR (2014) Alpha and gamma oscillations characterize feedback and feedforward processing in monkey visual cortex. Proc Natl Acad Sci U S A 111:14332-14341. CrossRef Medline

Vijayan S, Kopell NJ (2012) Thalamic model of awake alpha oscillations and implications for stimulus processing. Proc Natl Acad Sci U S A 109: 18553-18558. CrossRef Medline

Zhang Y, Ding M (2010) Detection of a weak somatosensory stimulus: role of the prestimulus mu rhythm and its top-down modulation. J Cogn Neurosci 22:307-322. CrossRef Medline 